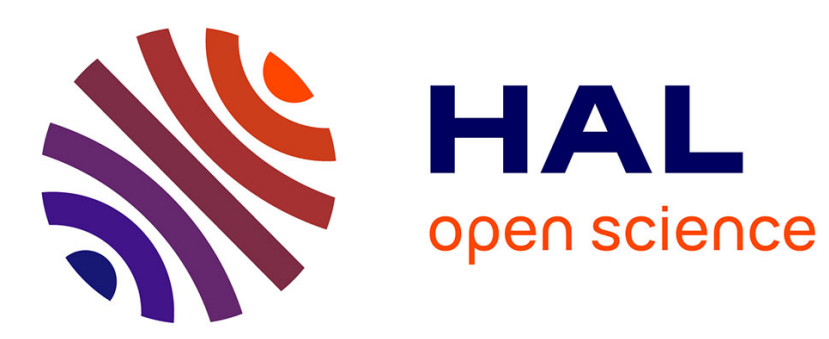

\title{
Les protéines de pois : de leur fonction dans la graine à leur utilisation en alimentation animale

\author{
C. Perrot
}

\section{To cite this version:}

C. Perrot. Les protéines de pois: de leur fonction dans la graine à leur utilisation en alimentation animale. Productions Animales, 1995, 8 (3), pp.151-164. hal-00896112

\section{HAL Id: hal-00896112 \\ https://hal.science/hal-00896112}

Submitted on 1 Jan 1995

HAL is a multi-disciplinary open access archive for the deposit and dissemination of scientific research documents, whether they are published or not. The documents may come from teaching and research institutions in France or abroad, or from public or private research centers.
L'archive ouverte pluridisciplinaire HAL, est destinée au dépôt et à la diffusion de documents scientifiques de niveau recherche, publiés ou non, émanant des établissements d'enseignement et de recherche français ou étrangers, des laboratoires publics ou privés. 
INRA Prod. Anim., 1995, 8 (3), 151-164

\section{PERROT}

INRA Laboratoire de Biochimie et Technologie des Protéines

BP 1627, 44316 Nantes Cedex
Les protéines de pois : de leur fonction dans la graine à leur utilisation en alimentation animale

Quelles sont les bases biochimiques pouvant expliquer la digestibilité relativement limitée de certaines protéines végétales ? Quelles améliorations peuvent apporter les différents traitements technologiques appliqués aux aliments contenant ces protéines? En prenant l'exemple du pois protéagineux, espèce ayant fait l'objet ces dernières années de très nombreux essais et recherches, cet article se propose de faire le point sur ces questions. De plus, un éclairage nouveau est apporté par l'étude de la structure et de la fonction physiologique des protéines de pois au sein de la graine.

Parmi les matières premières riches en protéines, substituts possibles au soja, le pois (Pisum sativum L.) a une place relativement importante, surtout en France où il représente $11 \%$ des matières azotées totales utilisées pour l'alimentation animale.

Le pois a fait l'objet d'essais d'incorporation dans des régimes pour animaux, en remplace-

\section{Résumé}

Riche en protéines, le pois est une matière première d'origine européenne particulièrement intéressante pour l'alimentation des animaux monogastriques. Dans la graine de pois, la principale fonction des protéines est de servir de réserve d'azote et d'acides aminés. Cette fonction engendre, pour ces protéines, certaines caractéristiques particulières, telles qu'une structure particulièrement compacte, ou une résistance à l'hydrolyse avant la germination. En alimentation animale, les protéines de pois présentent une digestibilité assez variable, généralement inférieure à celle d'aliments témoins (soja). La digestibilité des protéines peut être limitée à plusieurs niveaux : au niveau de l'hydrolyse par les enzymes digestives, au niveau de l'absorption des produits d'hydrolyse et au niveau de la réaction de l'animal à l'aliment, pouvant se traduire par une perte accrue de protéines endogènes. Différents facteurs ont été proposés pour expliquer la limitation de la digestibilité des protéines de pois : présence d'inhibiteurs trypsiques, de lectines, de fibres, structure particulière des protéines, antigénicité de ces protéines. L'application de traitements technologiques peut avoir des conséquences positives (dénaturation de protéines, inactivation d'inhibiteurs, perte de la structure cellulaire...) ou négatives (réticulation, insolubilisation de protéines) sur la digestibilité des protéines. ment du tourteau de soja ou d'autres protéines. Les animaux concernés sont essentiellement les monogastriques : porcs et volailles. Les résultats obtenus montrent une grande variabilité des performances zootechniques et, en particulier, une variabilité de la digestibilité des protéines de pois, celle-ci étant en général inférieure à celle des protéines témoins (soja) (Gatel 1992).

Une utilisation optimale du pois protéagineux en alimentation animale nécessite donc l'identification des facteurs responsables de la limitation de la digestibilité de ses protéines et, si possible, leur neutralisation, soit par la sélection variétale, soit par l'application de traitements technologiques.

Cet article étudie d'abord les protéines de pois en tant que réserves de la graine, en examinant leur structure, leur biosynthèse et leur utilisation lors de la germination. La deuxième partie est ensuite consacrée aux protéines de pois en tant qu'aliment pour les animaux monogastriques (porcs et volailles), en examinant les différents facteurs susceptibles de faire varier leur digestibilité. Enfin, la dernière partie de cette étude présente les conséquences de l'application de traitements technologiques sur la valeur nutritionnelle des protéines de pois. 


\section{1 / Les protéines de pois, réserves de la graine}

Connu depuis l'antiquité, le pois a d'abord été cultivé comme légume sec destiné à l'alimentation humaine. Très apprécié aussi comme légume frais (le «petit pois» est une graine cueillie avant maturité), il a connu un essor considérable à la suite du développement des industries de conserve et de surgélation. Le petit pois est aujourd'hui le premier légume de conserve en France. Le pois a été l'objet de nombreux travaux de recherche, les plus célèbres étant sans aucun doute ceux de Mendel (1865), sur la transmission héréditaire de certains caractères morphologiques (graine lisse ou ridée, couleur de la fleur...) qui ont posé les bases de la génétique moderne.

Parmi les milliers de variétés de pois existant, certaines ont été spécialement sélectionnées pour une utilisation en alimentation animale sur des critères de rendements de culture et de teneur élevée des graines en protéines, on parle alors de "pois protéagineux ». En 1993, la production française de pois protéagineux était de $3750000 \mathrm{t}$.

\section{1 / La graine de pois}

La graine est un organisme complexe, qui, à l'abri de ses téguments, contient un embryon figé dans sa croissance. Elle contient aussi les réserves qui lui permettront, lorsque les conditions seront favorables, de s'enraciner et de devenir une nouvelle plante.

La graine de pois est, du point de vue physiologique, une graine exalbuminée : contrairement aux céréales, elle ne contient pas d'albumen, tissu spécialisé dans l'accumulation des réserves, mais est totalement remplie, à maturité, par un embryon chargé de réserves dans lequel une différenciation est déjà esquissée (figure 1). Les réserves contenues dans la graine de pois sont des protéines ( 20 à $25 \%$ du poids sec), des glucides (amidon principalement : 30 à $50 \%$ du poids sec), et des lipides (moins de $2 \%$ du poids sec). La figure 2 présente une coupe histologique de graine de pois. Les cellules sont presque totalement remplies de réserves : l'amidon, stocké sous forme de grains d'amidons, de forme ovoïde et de diamètre de $30 \mu \mathrm{m}$ environ et les protéines, stockées dans des organites spécialisés, les corps protéiques, de forme sphérique et de diamètre de $2 \mu \mathrm{m}$ environ.

\section{2 / Composition des protéines de pois}

Les protéines du pois se classent en deux grandes familles selon les critères de solubilité définis par Osborne et Campbell (1898) : les globulines, solubles dans des tampons salins, et les albumines, solubles dans l'eau. Il existe aussi environ 10 à $15 \%$ de protéines insolubles. Les globulines représentent 55 à $65 \%$ des protéines totales du pois. Deux protéines

Figure 1. Développement de l'ovule de pois après fertilisation. Les chiffres correspondent à des stades arbitraires de développement, le stade 25 correspondant à une graine à maturité. L'embryon figure en noir. 1 : tégument séminal, 2 : paroi du sac embryonnaire, 3 : vacuole du sac embryonnaire, 4 : suspenseur. La barre représente toujours $1 \mathrm{~mm}$. D'après Marinos (1970).

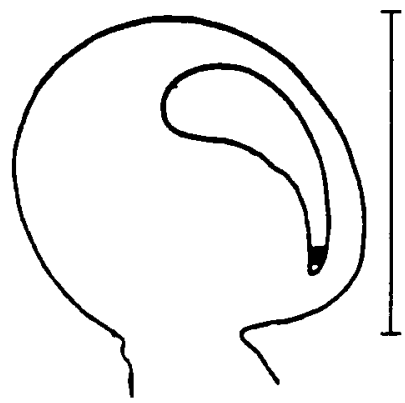

16

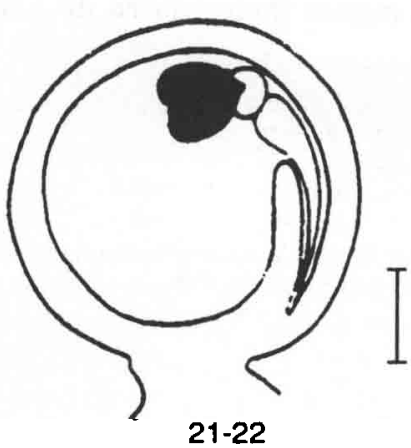

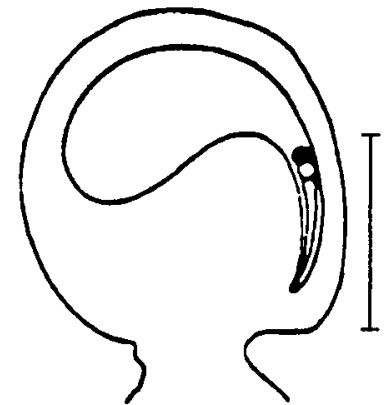

18

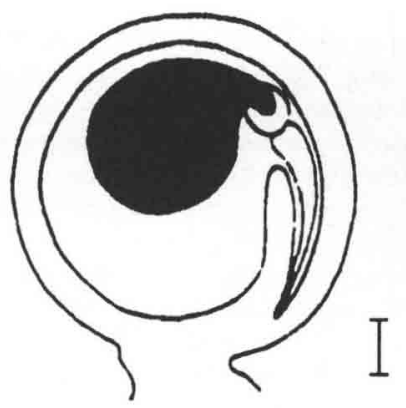

23

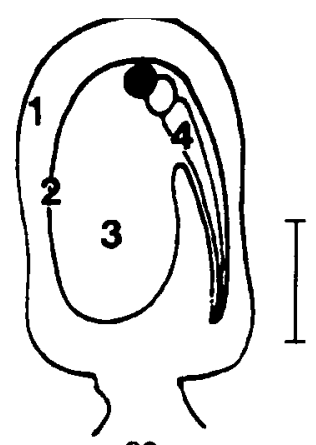

20

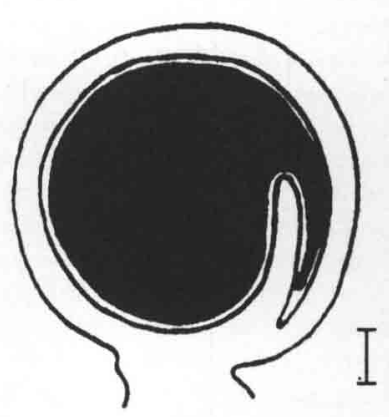

24 
forment cette famille : la légumine et la viciline. Elles appartiennent respectivement aux types de protéines « $11 \mathrm{~S}$ » et « $7 \mathrm{~S}$ », très largement répandus chez les plantes dicotylédones, et dont la structure et la séquence sont largement conservées entre espèces. La seconde famille est constituée par les albumines, représentant de 20 à $30 \%$ des protéines totales. Leur composition est beaucoup plus hétérogène que celle des globulines, mais il existe néanmoins 2 albumines majeures appelées PA1 et PA2. La composition en acides aminés des protéines de pois (tableau 1) montre que celles-ci sont globalement pauvres en acides aminés soufrés et en tryptophane. Les globulines ont des teneurs très élevées en acides aspartique, glutamique et leurs amides. Les albumines sont plus riches en acides aminés soufrés et en lysine. La teneur et la composition en protéines des graines de pois sont susceptibles de varier en fonction du génotype ou des conditions de culture des pois. L'effet des facteurs génotypiques est néanmoins prépondérant (Baniel 1993). Ainsi, les variétés ridées sont plus riches en viciline que les variétés lisses (Gueguen et Barbot 1988).

\section{3 / Structure des principales protéines de pois}

\section{a / Légumine (11 S)}

La légumine est une protéine de masse moléculaire élevée (de $330 \mathrm{kDa}$ à $400 \mathrm{kDa}$ ), composée de 6 sous-unités de type $\alpha-\beta$. Chaque sous-unité, de masse moléculaire de $60 \mathrm{kDa}$ environ, est composée d'un polypeptide $\alpha$ acide, de $40 \mathrm{kDa}$ environ, et d'un polypeptide $\beta$ basique de $20 \mathrm{kDa}$ environ (Gueguen 1991). Ces deux polypeptides sont liés

Tableau 1. Composition en acides aminés des protéines de pois (d'après Gwiazda et al 1980). Les résultats sont exprimés en grammes pour $16 \mathrm{~g}$ d'azote.

\begin{tabular}{|l|c|c|c|}
\hline $\begin{array}{l}\text { Acide } \\
\text { aminé }\end{array}$ & $\begin{array}{c}\text { Farine } \\
\text { de pois }\end{array}$ & $\begin{array}{c}\text { Fraction } \\
\text { albumines }\end{array}$ & $\begin{array}{c}\text { Fraction } \\
\text { globulines }\end{array}$ \\
\hline ASX & 12,25 & 1,90 & 12,99 \\
THR & 3,65 & 5,66 & 3,34 \\
SER & 4,79 & 5,03 & 5,30 \\
GLX & 17,41 & 14,95 & 18,66 \\
PRO & 3,91 & 4,46 & 4,36 \\
GLY & 4,29 & 5,97 & 3,89 \\
ALA & 4,06 & 5,85 & 3,97 \\
CYS & 1,39 & 3,15 & 0,80 \\
VAL & 4,69 & 4,41 & 4,73 \\
MET & 0,99 & 1,34 & 0,70 \\
ILE & 4,23 & 3,86 & 4,59 \\
LEU & 7,20 & 4,87 & 8,23 \\
TYR & 3,19 & 4,71 & 3,37 \\
PHE & 4,75 & 4,52 & 5,40 \\
TRP & 0,95 & 1,47 & 0,67 \\
LYS & 6,92 & 9,34 & 6,41 \\
HIS & 2,30 & 2,63 & 2,55 \\
ARG & 8,28 & 5,67 & 8,00 \\
\hline
\end{tabular}

Figure 2. Coupe histologique de graine de pois incluse dans la paraffine. Coloration par le Fast-green et l'iode. 1 : tégument séminal, 2 : grain d'amidon, 3 : protéines. Cliché Ben-Hdech (1993).

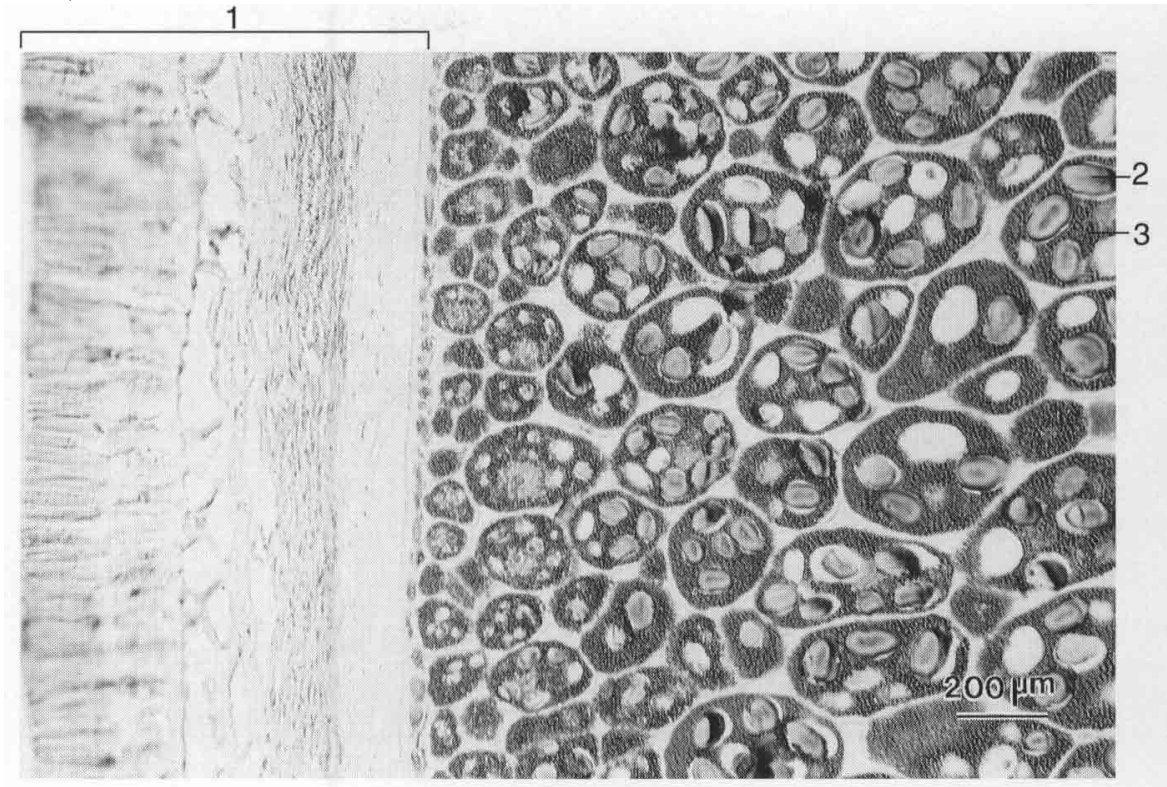

entre eux par un pont disulfure. La légumine possède une structure très compacte, rigide, riche en feuillets $\beta$ (Subirade et al 1994). Plietz et al (1984) ont proposé un modèle en antiprisme trigonal pour décrire la structure de cette molécule. Dans ce modèle, les polypeptides $\alpha$ seraient situés à l'extérieur de la molécule, tandis que les polypeptides $\beta$ constitueraient le cœur hydrophobe de la molécule. Ces traits généraux sont communs à toutes les protéines de type $11 \mathrm{~S}$, que l'on retrouve dans de très nombreuses espèces (haricot, soja, tournesol,...). Néanmoins, à l'intérieur d'une même espèce, il existe une très grande hétérogénéité moléculaire. Ainsi, il existe au moins 22 polypeptides acides et 11 polypeptides basiques différents chez le pois, variant selon leur taille et leur $\mathrm{pHi}$ (Matta et al 1981). Cette hétérogénéité de composition de la légumine de pois a des origines génétiques (au moins 10 gènes codent pour la légumine selon Boulter et al 1987) mais également post-traductionnelles (protéolyse, désamidation). Cette hétérogénéité moléculaire empêche la cristallisation de cette protéine.

\section{b / Viciline (7 S)}

La viciline de pois est une protéine oligomérique de masse moléculaire de $150 \mathrm{kDa}$

Feuillet $\beta$ : appelée aussi structure à feuillets plissés ; juxtaposition régulière face à face de chaînes polypeptidiques, stabilisée par l'existence de liaisons hydrogènes entre les résidus carbonyle (CO) d'une chaîne et amido (NH) d'une autre chaîne.

pHi : pH pour lequel la charge nette de la molécule est nulle; au dessous de son $\mathrm{pHi}$, la molécule est protonnée ; au dessus, elle est déprotonnée.

$\mathrm{S}$ : unité Svedberg (=10-13 s) ; caractérise la vitesse de sédimentation d'une macromolécule dans un champ centrifuge ; dépend de la masse de la molécule, et de sa capacité à diffuser (forme). 
environ. Elle est composée de polypeptides de $50 \mathrm{kDa}$ environ, et d'un grand nombre de polypeptides de plus faible masse moléculaire (33, 30, 19, 15, 13, 12,5 kDa) (Gueguen 1991). Sa structure (comme toutes les protéines de type $7 \mathrm{~S}$ ) est celle d'un trimère de sous-unités de $50 \mathrm{kDa}$. Il a en effet été montré que les polypeptides de la viciline de taille inférieure à $50 \mathrm{kDa}$ résultaient du clivage post-traductionnel d'un précurseur de $50 \mathrm{kDa}$. Comme la légumine, la viciline a une structure secondaire riche en feuillets $\beta$ (L'anson et al 1988).

Une autre globuline de type $7 \mathrm{~S}$, la conviciline, a été identifiée dans le pois. Elle présente de très grandes homologies de séquence avec la viciline. Sa structure est celle d'un trimère de sous-unités de $70 \mathrm{kDa}$.

Comme pour la légumine, il existe une très grande hétérogénéité moléculaire de la viciline. Selon Boulter et al (1987) il existerait au moins 15 gènes codant pour la viciline dans le pois.

\section{c / PA2 et PA1, les deux albumines majeures}

L'albumine de haut poids moléculaire, PA2, est un dimère de sous-unités de $25 \mathrm{kDa}$ environ. Chaque sous-unité est constituée d'une chaîne polypeptidique unique et possède trois résidus cystéines, dont deux forment un pont disulfure. La structure de cette protéine est compacte, riche en feuillets $\beta$ (Gruen et al 1987).

L'albumine de bas poids moléculaire, PA1, serait, selon Gatehouse et al (1985) un dimère de $11 \mathrm{kDa}$, composé de polypeptides de $6 \mathrm{kDa}$ environ. Cette protéine est exceptionnellement riche en soufre, puisque selon Higgins et al (1986), elle contiendrait $50 \%$ des acides aminés soufrés totaux du pois.

\section{d / Lectines}

Les lectines appartiennent à la famille des albumines et représentent 2,5\% environ des protéines du pois (Masson et al 1986). Ce sont des protéines tétramériques de $50 \mathrm{kDa}$ environ, composées de deux chaînes polypeptidiques légères de $7 \mathrm{kDa}(\alpha)$ et de deux chaînes lourdes ( $\beta$ ) de $17 \mathrm{kDa}$. Les lectines de pois ne contiennent pas d'acides aminés soufrés et leur structure secondaire contient une proportion élevée de feuillets $\beta$ (Goldstein et Poretz 1986).

Le terme de lectines vient du latin " legere" qui signifie " choisir». En effet, ces protéines, très largement présentes dans le règne végétal, se lient de manière spécifique à certains résidus glucidiques. La spécificité de liaison varie en fonction de l'espèce végétale (par exemple glucose/mannose pour les lectines de pois, et galactose/N-acetylgalactosamine pour celles de haricot). Cette propriété en fait de remarquables outils utilisés en biologie pour le typage des groupes sanguins, l'investigation des structures de surface des cellules, la transformation de cellules.

\section{e / Inhibiteurs trypsiques}

Les inhibiteurs trypsiques de pois sont également des albumines et représentent, en général, moins de $2 \%$ des protéines totales de la graine. Ce sont des protéines monomériques de faible masse moléculaire (inférieure à $10 \mathrm{kDa}$ ), capables de se lier de manière irréversible aux sites actifs de la trypsine et de la chymotrypsine (deux sites indépendants) (Birk et Smirnoff 1992). Chaque polypeptide contient 7 ponts disulfures (Huisman et Jansman 1991).

\section{4 / Synthèse et transport des protéines dans la graine}

La synthèse des protéines dans la graine commence 9 à 12 jours après la floraison. La phase d'accumulation de ces protéines a lieu durant la phase de croissance qui suit la division cellulaire rapide de l'embryon. Toutes les protéines ne sont pas synthétisées au même moment: la viciline est synthétisée en premier, lectines et légumine s'accumulent ensuite successivement (Wenzel et al 1993).

La légumine, la viciline et les lectines sont transportées, via l'appareil de Golgi vers les corps protéiques, organites de stockage des protéines, d'origine vacuolaire. Synthétisées sous forme de chaînes polypeptidiques, elles acquièrent leur structure finale (oligomérique, clivage en différents polypeptides) au cours du transport et du stockage.

Il existe peu d'informations concernant la synthèse et la localisation des albumines dans la graine. Selon Higgins et al (1986), PA1 serait localisée dans les corps protéiques. PA2 serait au contraire une protéine cytoplasmique (Gruen et al 1987). La localisation des inhibiteurs trypsiques n'a pas été établie.

\section{5 / Mobilisation des protéines de réserve lors de la germination}

La germination se caractérise par une imbibition d'eau et une réactivation du métabolisme de la graine. La légumine, la viciline, et probablement l'albumine PA1 sont des protéines de réserve, localisées dans les corps protéiques. Ceux-ci ne sont pas des organites inertes, mais sont capables de se transformer en lysosomes. Dans les premiers jours de croissance de l'embryon, les corps protéiques enflent, puis, sans que leur membrane ne soit rompue, l'hydrolyse des protéines commence.

Shutov et Vaintraub (1987) ont montré que trois protéases au moins intervenaient dans la dégradation des protéines de réserve de type $11 \mathrm{~S}$ et $7 \mathrm{~S}$ : une protéase " $\mathrm{A}$ " (à cystéine), synthétisée de novo à la germination, réalise une protéolyse limitée des protéines. Cette protéolyse limitée les rend ensuite susceptibles à l'attaque par d'autres protéases, dont certaines étaient déjà présentes dans la graine avant germination. Les travaux réalisés sur d'autres plantes (sarrasin, haricot...) montrent également que deux protéases au 
moins interviennent pour hydrolyser les protéines de réserves.

Si l'albumine PA1 paraît dégradée lors de la germination du pois (Higgins et al 1986), l'albumine PA2, persiste de manière durable (Schrœeder 1984). Le rôle de PA2 reste inconnu.

Les lectines persisteraient également après la germination, selon Croy et al (1984). Parmi les hypothèses faites sur le rôle des lectines dans la plante, on trouve des fonctions supposées de régulateurs de croissance, de transporteurs des glucides ou des protéines, de promoteurs de la symbiose avec les bactéries fixatrices d'azote. Un rôle de défense de la graine a également été envisagé ; la notion d'anticorps de plantes a été employée.

Le rôle central joué par les protéases au cours de la germination peut laisser supposer que les inhibiteurs de protéases auraient la fonction de maintenir celles-ci inactives dans la graine. Cependant, aucune interaction n'a jamais été mise en évidence entre inhibiteurs de protéases et protéases intervenant dans la germination (Royer 1975). D'autres rôles ont été proposés pour ces inhibiteurs, celui de défense contre les insectes, ou celui de régulateur de la transcription de l'ADN : des protéines de type trypsine sont en effet capables d'agir sur la transcription des gènes en hydrolysant les histones (Royer 1975). C'est peut-être cette propriété des inhibiteurs trypsiques qui serait à l'origine de leurs propriétés anti-carcinogènes (Birk et Smirnoff 1992).

En conclusion, on peut retenir que, du point de vue physiologique, les principales protéines du pois sont des protéines de réserve, dont le rôle est d'être une source d'azote, de carbone, de soufre pour les besoins futurs de l'embryon. Leurs principales caractéristiques sont résumées dans le tableau 2. Selon Higgins (1984), les principales caractéristiques des protéines de réserve sont les suivantes : une teneur élevée en azote (richesse en glutamine, asparagine), une structure compacte et une capacité à l'agrégation permettant un "compactage économique ", une résistance à l'hydrolyse avant la germination, mais une susceptibilité à l'hydrolyse au moment où l'embryon a besoin d'utiliser ses réserves. En ce qui concerne l'hydrolyse de protéines de ce type, on peut remarquer que la conjonction de plusieurs enzymes est toujours nécessaire pour assurer leur mobilisation à la germination. Enfin, on remarque aussi la très grande hétérogénéité intrinsèque de ces différentes protéines.

\section{2 / Le pois : aliment pour les animaux monogastriques}

\section{1 / Résultats obtenus : performances zootechniques et digestibilité des protéines}

Les différents essais de régimes à base de pois réalisés in vivo font état d'une grande variabilité de résultats, aussi bien en ce qui concerne les performances zootechniques des animaux que le coefficient de digestibilité des protéines (Quéméré 1990, Gatel 1992, UNIPITCF 1993). Cette grande variabilité de résultats a des causes méthodologiques (Gatel 1992), mais provient aussi de la variabilité de composition de la matière première et de la réponse de l'animal à celle-ci.

Dans une synthèse récente des essais français et étrangers sur l'utilisation du pois par les porcins, Quéméré (1990) rapporte qu'une incorporation de pois à un taux élevé $(40 \%)$ ne provoque pas, en moyenne, de baisse de performances chez les porcs en croissancefinition, à condition cependant que les régimes soient supplémentés en acides aminés essentiels (Met et Trp). Chez les porce-

Tableau 2. Structures et fonctions des principales protéines de la graine (1: Perrot 1994, $2:$ Masson et al 1986, 3 : Tomé et al 1981), nd : non déterminé.

\begin{tabular}{|c|c|c|c|c|}
\hline Nom & Structure & Teneur & Rôle & Germination \\
\hline Légumine & $\begin{array}{l}\text { Hexamère de } 360 \mathrm{kDa} \\
\text { Compacte, riche en feuillets } \beta \\
1 \text { pont } \mathrm{S}-\mathrm{S}\end{array}$ & 23 à $41 \%^{1}$ & Réserve & Dégradée \\
\hline Viciline & $\begin{array}{l}\text { Trimère de } 150 \mathrm{kDa} \\
\text { Compacte, riche en feuillets } \beta \\
\text { Pas de pont S-S }\end{array}$ & 24 à $37 \%^{1}$ & Réserve & Dégradée \\
\hline $\begin{array}{l}\text { Albumine } \\
\text { majeure PA1 }\end{array}$ & $\begin{array}{l}\text { Dimère de } 11 \mathrm{kDa} \\
\text { nd } \\
\text { nd }\end{array}$ & 5 à $9 \%^{1}$ & $\begin{array}{c}\text { Réserve } \\
\text { de soufre? }\end{array}$ & Dégradée \\
\hline $\begin{array}{l}\text { Albumine } \\
\text { majeure PA2 }\end{array}$ & $\begin{array}{l}\text { Dimère de } 50 \mathrm{kDa} \\
\text { Compacte, riche en feuillets } \beta \\
1 \text { pont } S-S\end{array}$ & 10 à $20 \%^{1}$ & nd & Peu dégradée \\
\hline Lectines & $\begin{array}{l}\text { Tétramère de } 50 \mathrm{kDa} \\
\text { Compacte, riche en feuillets } \beta \\
\text { Pas de pont } \mathrm{S}-\mathrm{S}\end{array}$ & $2,5 \%^{2}$ & nd & Peu dégradée \\
\hline $\begin{array}{l}\text { Inhibiteurs } \\
\text { trypsiques }\end{array}$ & $\begin{array}{l}\text { Monomère de } 7 \mathrm{kDa} \\
\text { Compacte } \\
7 \text { ponts S-S }\end{array}$ & $<2 \%^{3}$ & nd & nd \\
\hline
\end{tabular}


lets, des performances de croissance réduites ont été observées pour des taux d'incorporation supérieurs à $15-20 \%$. Chez le poulet, Barrier-Guillot et al (1992) rapportent une baisse de performance des poulets recevant un régime à base de pois $(30 \%)$ par rapport à ceux recevant un régime témoin.

Les coefficients de digestibilité iléale apparente de l'azote et des acides aminés du pois cru, chez le porc, sont en général légèrement inférieurs à ceux de la farine de soja (Gatel 1992, UNIP-ITCF 1993) (tableau 3). Chez le porcelet, Le Guen (1993) rapporte un coefficient de digestibilité apparente de $69 \%$ pour les protéines d'un régime à base de pois cru contre $82 \%$ pour un régime témoin (farine de poisson).

D'un point de vue pratique, l'existence d'une variabilité non maîtrisée oblige les fabricants d'aliments du bétail à prendre des marges de sécurité importantes. C'est pourquoi de nombreuses recherches ont actuellement pour but l'identification du ou des facteurs du pois responsables de la limitation de la digestibilité des protéines, et la quantification de leur part de responsabilité dans les différences observées.

\section{2 / Bases biochimiques expliquant la limitation de la digestibilité des protéines}

La digestibilité des protéines peut être limitée à plusieurs niveaux : l'hydrolyse des protéines par les enzymes du tractus digestif peut-être incomplète, l'absorption des produits d'hydrolyse peut être réduite par des perturbations de la perméabilité de la barrière intestinale, enfin, l'aliment peut induire une réaction physiologique de l'animal, entraînant, par exemple, une perte de protéines endogènes. Les différentes hypothèses ici regroupées seront examinées en prenant en compte leur influence possible à ces différents niveaux.

\section{a / Inhibiteurs trypsiques}

Les inhibiteurs trypsiques sont les «facteurs antinutritionnels " les plus largement étudiés. Les premières protéines de ce type furent isolées dans le soja (Kunitz 1945), mais on les trouve très largement répandues dans le règne végétal. Le pois serait une des

Tableau 3. Coefficients de digestibilité iléale apparente de l'azote et des acides aminés chez le porc avec anastomose iléorectale (Rhône Poulenc nutrition animale, cité par Gatel 1992).

\begin{tabular}{|l|c|c|}
\hline & $\begin{array}{c}\text { Pois } \\
\text { (printemps) }\end{array}$ & $\begin{array}{c}\text { Farine } \\
\text { de soja }\end{array}$ \\
\hline Azote & 0,743 & 0,798 \\
Lysine & 0,815 & 0,847 \\
Méthionine & 0,767 & 0,862 \\
Cystine & 0,621 & 0,762 \\
Thréonine & 0,710 & 0,786 \\
\hline
\end{tabular}

légumineuses en contenant le moins, environ 8 fois moins que le soja cru. Il existe cependant des différences importantes entre cultivars, certaines variétés de pois de type « hiver " contenant 2 à 3 fois plus d'inhibiteurs trypsiques que les variétés de printemps (Leterme et al 1992). Le lien entre inhibition de croissance et inhibiteurs trypsiques a été logiquement établi par la constatation qu'un régime à base de soja cru était incapable de répondre aux besoins nutritionnels du rat en croissance. Chez le porc, on montre que les performances des animaux recevant un régime à base de pois riches en inhibiteurs trypsiques sont inférieures à celles d'animaux recevant des pois pauvres en inhibiteurs trypsiques (Leterme et al 1990 , Perez et Bourdon 1992).

La responsabilité unique des inhibiteurs trypsiques dans la limitation de la digestibilité des protéines de pois est cependant très controversée. Le retrait sélectif de ces protéines dans le soja cru améliore les performances de croissance chez le rat, mais ne permet pas de rétablir un niveau identique à celui du régime témoin (Kakade et al 1973). Le Guen (1993) a montré que ces facteurs n'étaient pas les seuls responsables dans la limitation de la digestibilité des protéines de pois chez le porcelet : en effet, le coefficient de digestibilité iléale apparente des protéines du pois entier est de $69 \%$; celui d'un isolat de protéines de pois est de $84 \%$; celui d'un isolat auquel on ajoute une quantité d'inhibiteurs trypsiques équivalente à celle du pois entier est de $77 \%$. Les inhibiteurs trypsiques n'expliqueraient donc que la moitié de la limitation de la digestibilité des protéines du pois chez le porcelet. D'autre part, les poulets sont en général très peu sensibles aux variations de teneurs en inhibiteurs trypsiques des pois (Carré et al 1991, Barrier-Guillot et al 1992).

Le mécanisme par lequel les inhibiteurs trypsiques diminuent la digestibilité des protéines n'est pas clairement établi : deux types de mécanismes au moins sont susceptibles d'être impliqués (Huisman et Jansman 1991). D'une part, les inhibiteurs se liant de manière irréversible à la trypsine, la digestibilité apparente des protéines peut être réduite par défaut d'hydrolyse des protéines alimentaires. D'autre part, la digestibilité apparente peut être réduite par la présence, dans les digestas, d'une quantité importante de protéines endogènes sécrétées par le pancréas : il existe en effet un mécanisme de régulation négative, par voie hormonale, de la sécrétion pancréatique ; cette régulation est gouvernée par la quantité de trypsine libre. Lorsque la trypsine est liée irréversiblement à des inhibiteurs trypsiques, cette rétro-régulation ne peut plus avoir lieu et la sécrétion pancréatique est augmentée. Une hypertrophie du pancréas et une sécrétion accrue, en réponse à l'ingestion d'un régime riche en inhibiteurs trypsiques, ont été constatées chez la souris, le rat, le cobaye, le poulet. Chez les animaux de plus grande taille (porc, chien, veau), ces phénomènes n'ont pas été observés (Huisman 1991). 


\section{b / Lectines}

Les propriétés de liaison spécifique de certains composés glucidiques par les lectines sont susceptibles d'avoir une incidence physiologique ou nutritionnelle. Les lectines sont tenues pour responsables de la toxicité, pour les hommes ou pour les animaux, de légumes consommés crus ou improprement cuits : c'est le cas du haricot (Phaseolus vulgaris), du pois-sabre (Canavalia ensiformis), du ricin (Ricinus communis). Les lectines de Phaseolus vulgaris et celles de Canavalia ensiformis (Concanavaline A) ont été les plus largement étudiées. Résistantes à l'hydrolyse pepsique, elles sont capables de se lier à des récepteurs spécifiques des cellules épithéliales de l'intestin (Nakata et Kimura 1985, Pusztai et al 1991). Cette liaison engendre des lésions locales, un développement anormal des microvillosités, et altère l'absorption des nutriments. Elle peut conduire aussi à une infiltration de bactéries, et à une internalisation des lectines, permettant leur entrée dans le système sanguin. Les lectines de pois, cependant, ne semblent pas provoquer de dommages à la muqueuse intestinale, ni d'altération dans l'absorption des nutriments (Bertrand et al 1988). Selon cet auteur, la protection des cellules de l'épithélium intestinal serait due à la neutralisation des lectines par les nombreux glycoconjugués présents dans l'aliment, et liberés lors de la digestion. Selon Huisman et Jansman (1991) et Grant et Van Driessche (1993) la différence de toxicité entre lectines de pois et lectines de haricot serait due à leurs spécificités de liaison : glucose/mannose pour le pois, galactose/ $\mathrm{N}$-acetylgalactosamine pour le haricot; les cellules matures des microvillosités intestinales portent généralement des résidus glucidiques complexes, sites de liaisons pour les lectines de haricot.

D'une manière générale, chez le pois, les lectines ne sont pas considérées comme d'importants facteurs antinutritionnels (UNIPITCF 1993).

\section{c / Tanins}

L'effet négatif des tanins sur la digestion des protéines a été démontré chez le porc (Grosjean et al 1991) et chez le poulet (Lacassagne et al 1991). Les tanins sont des composés polyphénoliques, de masse moléculaire de $500 \mathrm{Da}$ à $3000 \mathrm{Da}$; ils ont la capacité de former des complexes avec différentes macromolécules, dont les protéines. Ils sont ainsi susceptibles d'affecter l'hydrolyse des protéines, en se liant aux protéines alimentaires ou aux enzymes. De plus, ils semblent provoquer des sécrétions salivaires accrues.

Seuls les pois à fleurs colorées contiennent des tanins (UNIP-ITCF 1993); c'est le cas des pois fourragers dont les graines ne sont pas utilisées en France pour l'alimentation des monogastriques.

\section{d / Fibres}

La teneur en fibres d'un aliment exerce en général une influence négative sur le coefficient de digestibilité apparente des protéines chez le porc (Stanogias et Pierce 1985, Hall et al 1988). Chez le poulet, Carré et al (1991) supposent que le facteur explicatif de la limitation de la digestibilité des protéines de pois est lié aux parois cellulaires, celles-ci diminuant l'accessibilité des enzymes aux nutriments (protéines et amidon). Chez le porcelet, Le Guen (1993) fait également l'hypothèse que la structure cellulaire du pois serait un facteur diminuant la digestibilité des protéines. Cette baisse du coefficient de digestibilité apparente des protéines en présence de fibres peut être liée cependant à d'autres causes que la limitation de leur accessibilité : transit accéléré, adsorption de protéines sur les fibres (Perrot 1994), synthèse accrue de protéines endogènes, synthèse accrue de protéines bactériennes dans le cas de fibres fermentescibles (Darcy 1984).

\section{e / Phytates}

Les phytates sont la forme de réserve du phosphore dans les plantes; ils représentent de 1 à $5 \%$ du poids sec des graines de légumineuses (Huisman et Jansman 1991). Les phytates ont des propriétés chélatantes, et sont supposés interagir avec les minéraux et les protéines (Gorospe et al 1992). Un effet faiblement inhibiteur des phytates a été démontré sur la protéolyse in vitro, mais aucun effet n'a pu être mis en évidence in vivo (Knuckles et al 1989).

\section{f / Structure résistante des protéines de pois}

La structure des principales protéines de pois est en général compacte, globulaire, riche en feuillets $\beta$ (voir paragraphe 1.3 ). Selon certains auteurs, la faible valeur nutritionnelle des protéines de légumineuses pourrait être en partie due à ces contraintes structurales. Plumb et Lambert (1990) ont montré que les protéines de type $11 \mathrm{~S}$, dont la légumine de pois, présentent une grande résistance à l'hydrolyse par la trypsine : le polypeptide $\alpha$ est clivé en une région très limitée, le polypeptide $\beta$ est complètement résistant. La légumine de pois est plus susceptible à l'hydrolyse par la pepsine, probablement en raison de la déstabilisation de sa structure à $\mathrm{pH}$ acide (Perrot 1994). Dans tous les cas, c'est le polypeptide $\beta$, plus hydrophobe (plus compact) qui présente le plus de résistance à l'hydrolyse.

Parmi les protéines de type $7 \mathrm{~S}$ (comme la viciline), c'est la protéine du haricot (Phaseolus vulgaris), la phaséoline, qui a été très largement étudiée. Bradbear et Boulter (1984) ont montré que la phaséoline native est très résistante à l'hydrolyse par la trypsine. Dans des digestas iléaux de porcs, Begbie et Ross (1993) ont retrouvé des polypeptides de 20 à $30 \mathrm{kDa}$, issus de la phaséoline. Cependant, 
une extrapolation à la viciline de pois des résultats obtenus sur la phaséoline est assez difficile. En effet, la phaséoline du haricot est un trimère de sous-unités intactes de $50 \mathrm{kDa}$, alors que les sous-unités de la viciline sont clivées post-traductionnellement en polypeptides de plus faible poids moléculaire. De plus, la phaséoline est beaucoup plus glycosylée que la viciline. Ces caractéristiques de la phaséoline lui confèrent probablement une résistance supérieure à l'hydrolyse enzymatique. La viciline de pois est en effet très susceptible à l'hydrolyse par la trypsine et, contrairement à la légumine, elle paraît résister davantage à la pepsine (Perrot 1994).

L'albumine PA2 est résistante à l'hydrolyse enzymatique par la trypsine (Gruen et al 1987). Ce résultat a été confirmé, mais il a été également montré que l'albumine PA2 était très susceptible à l'hydrolyse par la pepsine, probablement en raison d'une déstabilisation de sa structure à $\mathrm{pH}$ acide (Perrot 1994). Il n'existe pas, à notre connaissance, de travaux concernant l'albumine PA1.

Dans le chapitre consacré aux lectines, nous avons mentionné leur résistance à l'hydrolyse pepsique (Nakata et Kimura 1985 , Pusztai et al 1991). Elles sont également résistantes à l'hydrolyse par la trypsine et la chymotrypsine (Perrot 1994). Cette résistance peut s'expliquer par la structure compacte de ces protéines, mais aussi par une possible protection par liaison de ligands (sucres, protéines glycosylées...).

La structure des inhibiteurs trypsiques de pois ( 7 ponts disulfure) leur confère également une grande résistance à l'hydrolyse enzymatique (Bradbear et Boulter 1984, Weder 1986). Leur activité inhibitrice est entièrement conservée après $3 \mathrm{~h}$ d'hydrolyse par la pepsine (Perrot 1994).

On peut donc conclure que les protéines de pois (et probablement celles d'autres légumineuses) présentent une relative résistance à l'hydrolyse enzymatique. Néanmoins, compte tenu de ce qui précède, il semble que la conjonction des effets de la pepsine et de la trypsine soit efficace pour hydrolyser la majeure partie des protéines du pois : légumine, viciline, albumine PA2. Ceci peut rappeler les événements de la germination au cours de laquelle plusieurs protéases interviennent pour mobiliser les protéines de réserve du pois. Par contre, les inhibiteurs trypsiques et les lectines ( 3 à $5 \%$ des protéines totales) semblent bien constituer une source d'acides aminés (notamment soufrés) non disponibles pour l'animal.

\section{g / Réaction d'hypersensibilité des animaux}

Les protéines des plantes, et en particulier celles des légumineuses, sont susceptibles de provoquer des réactions de type allergique chez les jeunes animaux. L'hypersensibilité aux protéines de soja du veau préruminant a été très étudiée. Ces réactions allergiques concernent environ $20 \%$ des animaux, et conduisent à des performances zootechniques médiocres, à une altération de la paroi intestinale, une dégradation de l'état de santé général, parfois même à la mort (Lallès 1993). Dans le sérum de veaux recevant du soja dans leur alimentation, on constate une élévation du taux d'anticorps circulants contre les globulines du soja: glycinine et conglycinine (Mathis 1991). Ces phénomènes de réponse immunologique sont également observés chez le porcelet, mais elles sont généralement plus transitoires (Dreau 1994). Chez le veau recevant du pois, on constate la formation d'anticorps contre la légumine, et très peu contre la viciline, mais pas de signes cliniques (Nunes Do Prado et al 1989). Chez les porcelets, on constate aussi une formation d'anticorps contre les protéines de pois (Hamer et al 1992); la fraction albumine du pois, et notamment une albumine "de $29 \mathrm{kDa}$ ", que nous identifions comme PA2, serait très impliquée dans la réponse immunologique des porcs (Gruppen et al 1993). Ces animaux ne présentent pas non plus de signes cliniques.

En conclusion, on peut donc dire que le pois est une légumineuse ayant une teneur assez élevée en protéines ( $24 \%$ de son poids sec), une teneur élevée en lysine, et des teneurs faibles en acides aminés soufrés, et en tryptophane. Il se caractérise aussi par des coefficients de digestibilité des protéines assez variables, en général inférieurs à ceux du soja (Gatel 1992). Pour tenter d'expliquer cette variabilité, et cette limitation de la digestibilité des protéines, de nombreux facteurs ont été évoqués; leurs effets possibles sont résumés sur la figure 3 . Parmi ces facteurs, seuls les inhibiteurs de protéases sont actuellement considérés comme importants. Cette importance est encore relative car seuls les porcs paraissent y être sensibles, et les inhibiteurs de protéases n'expliqueraient que la moitié de la limitation de la digestibilité des protéines de pois (Le Guen 1993). De plus, deux études récentes semblent montrer que leur digestibilité réelle serait élevée (de l'ordre de $90 \%$ ) et que leur faible coefficient de digestibilité apparente serait surtout dû à une augmentation des pertes de protéines endogènes (Huisman 1991, Le Guen 1993). De nombreuses recherches sont actuellement menées dans le but d'identifier les facteurs responsables de la limitation de la digestibilité des protéines de pois.

\section{3 / Effets des traitements technologiques sur la digestibilité des protéines de pois}

Différents types de traitements technologiques sont susceptibles d'être appliqués au pois. Parmi ceux-ci, on trouve le broyage (systématiquement appliqué), la granulation (à froid ou à chaud), l'autoclavage, la cuissonextrusion, ainsi que des technologies sépara- 
Figure 3. Sites et modes d'actions supposés de différents facteurs susceptibles de limiter la digestibilité des protéines de pois dans le tractus digestif d'un monogastrique (adapté de Huisman et Jansman 1991).

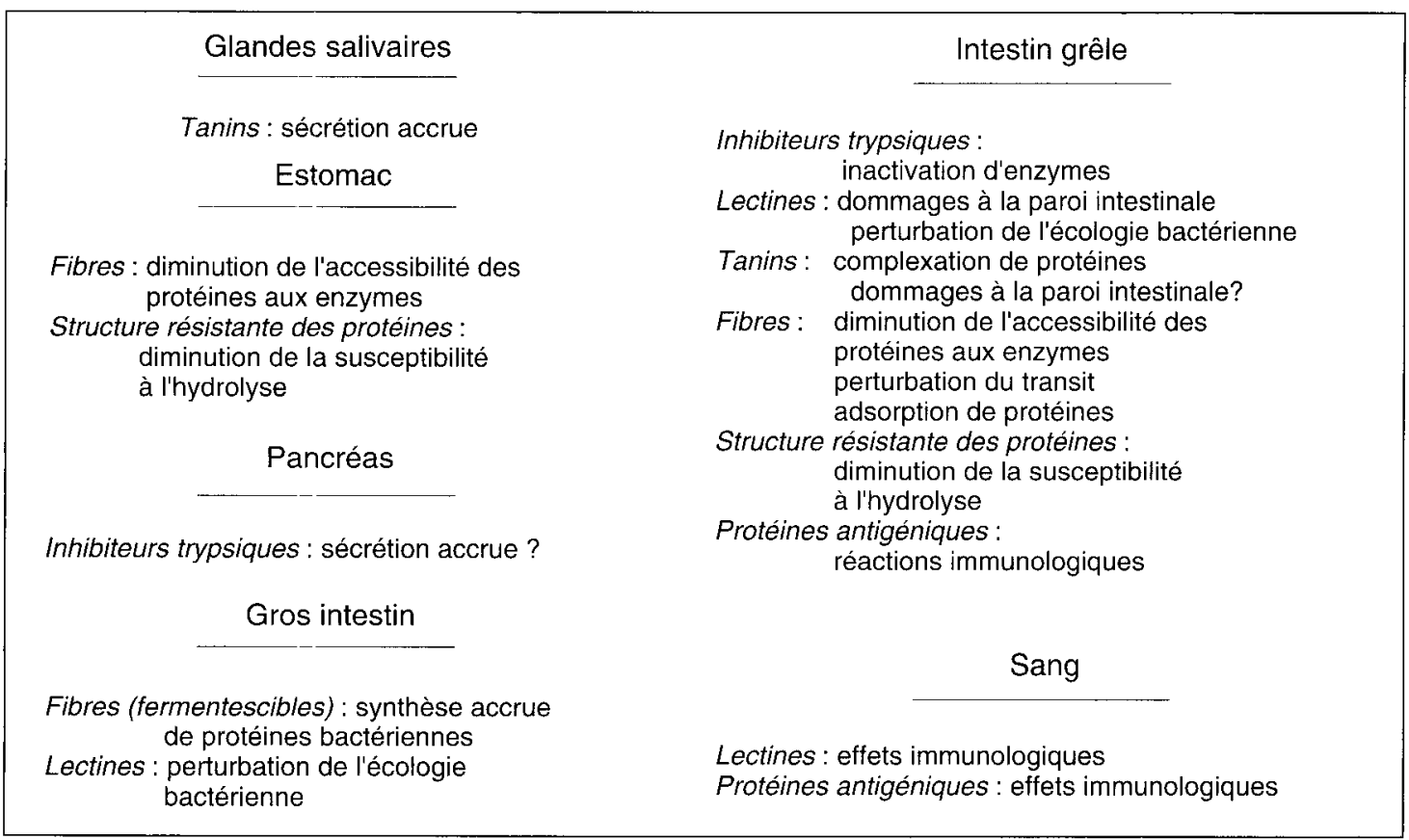

tives visant à séparer les constituants principaux du pois (amidon, protéines, fibres). Dans ce chapitre, non exhaustif, nous traiterons successivement des effets attendus (et observés) du broyage, des traitements thermiques ou thermo-mécaniques, et des technologies séparatives sur la digestibilité des protéines de pois, en essayant notamment de les relier aux différentes hypothèses décrites plus haut.

\section{1 / Broyage}

Le broyage détruisant une partie des structures cellulaires de la graine, on peut s'attendre à ce que l'hydrolyse des protéines soit favorisée par la diminution de la taille des particules de pois, c'est-à-dire lorsqu'on permet une plus grande accessibilité des protéines aux enzymes digestives. Néanmoins, plusieurs études réalisées chez le poulet (Lacassagne et al 1991, Conan et al 1992) montrent que la diminution de la taille moyenne des particules d'une farine de pois (respectivement de 500 à $160 \mu \mathrm{m}$ et de 800 à $300 \mu \mathrm{m})$ ne provoque pas d'amélioration de la digestibilité des protéines, alors que la digestibilité de l'amidon est significativement améliorée. Ceci peut être dû à la physiologie digestive particulière de ces animaux (rebroyage dans le gésier). De plus, la taille moyenne des plus petites particules de ces études (300 ou $160 \mu \mathrm{m}$ ) est supérieure ou de l'ordre de celle des cellules de la graine de pois. Dans une farine ayant une taille moyenne de particules de $250 \mu \mathrm{m}$ (autour de laquelle peut s'étendre une assez large distribution), des structures cellulaires intactes sont encore visibles (figure 4a). On conçoit assez bien que les grains d'amidons, plus gros et plus lourds, puissent «sortir» de ce type de structure. Par contre, les corps protéiques (diamètre $=2 \mu \mathrm{m}$ ) y seraient davantage retenus. Avec une mouture beaucoup plus fine (taille moyenne de $30 \mu \mathrm{m}$, obtenue par broyage cryogénique), nous avons obtenu une libération totale des corps protéiques dans le milieu (figure 4b) (Perrot 1994).

\section{2 / Effets des traitements thermiques}

D'une manière générale, chez le porc, on ne constate pas d'amélioration de la digestibilité

Figure 4 a. Coupe histologique de farine de pois broyée 1 min avec le broyeur IKA (broyage grossier). Microscopie photonique après coloration par le Fastgreen. Cliché Perrot (1994).

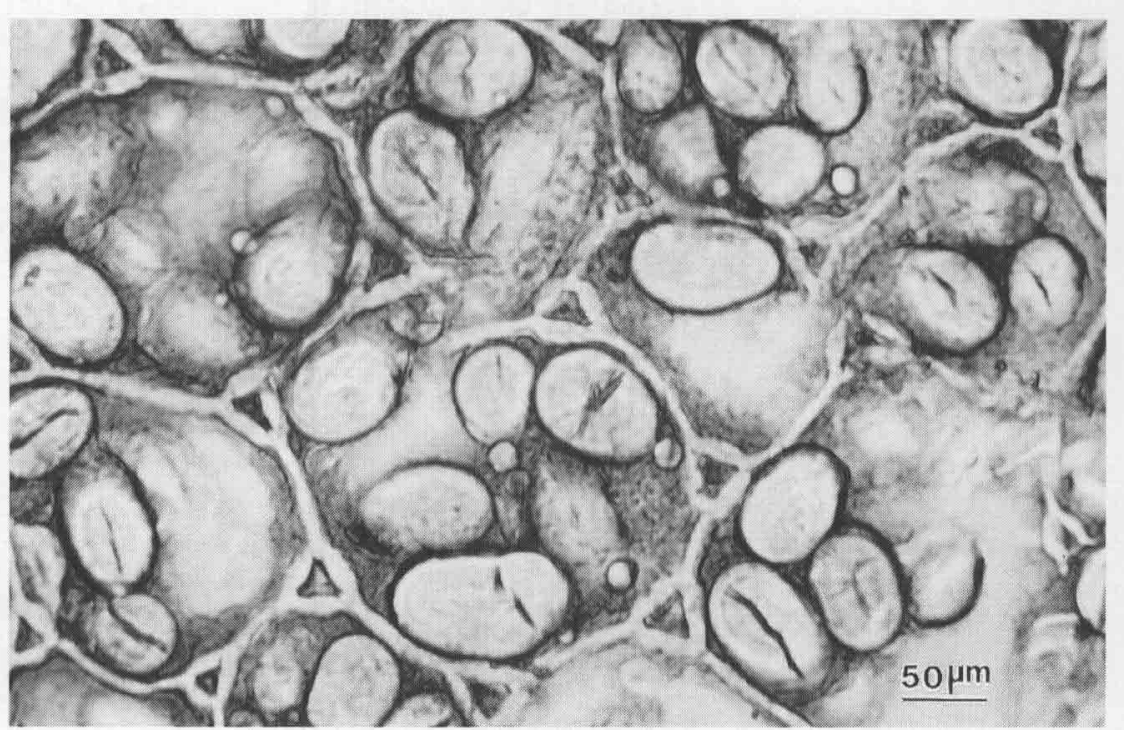


Figure $4 \mathrm{~b}$. Coupe histologique de farine de pois broyée 1 min avec le broyeur IKA puis 3 min avec le broyeur cryogénique. Microscopie photonique après coloration par le Fast-green. Cliché Perrot (1994).

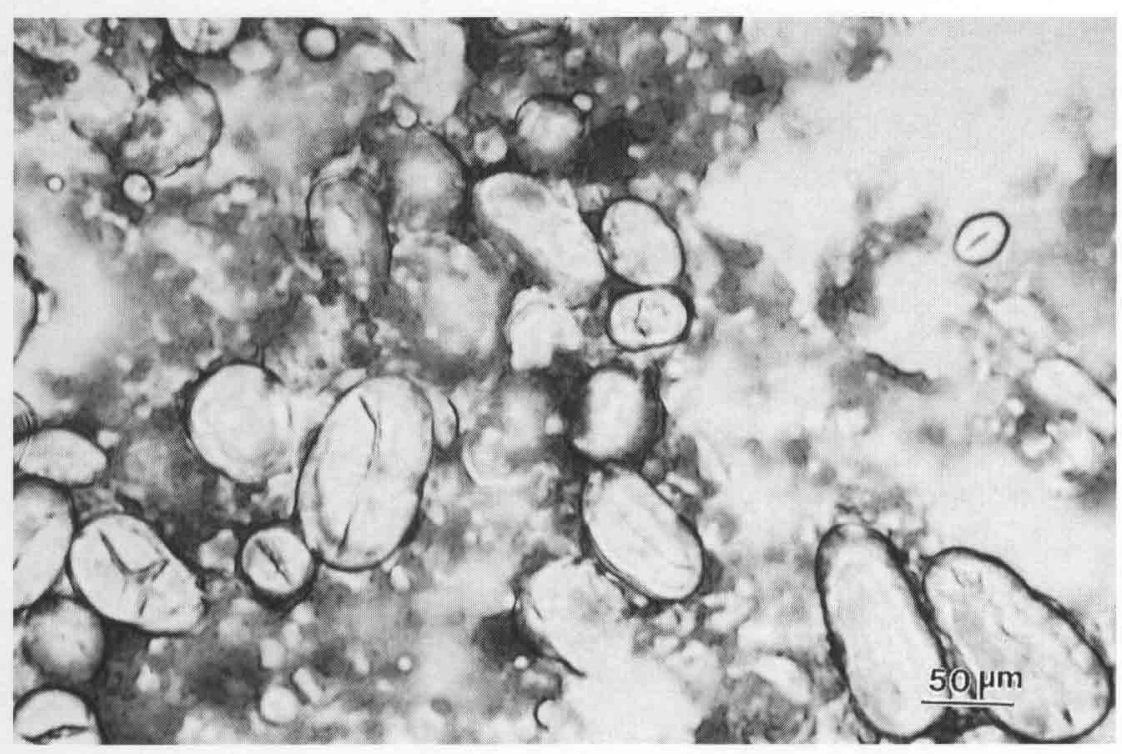

des protéines de pois après différents traitements thermiques (granulation, extrusion, autoclave...) (Gatel 1992). Une des rares études montrant une amélioration notable de la digestibilité des protéines chez le porcelet après cuisson-extrusion concernait un pois riche en inhibiteurs trypsiques (BengalaFreire et al 1991). Chez le poulet, la digestibilité des protéines est significativement améliorée $(+1$ à $5 \%)$ par une granulation à la vapeur des farines de pois (Carré et al 1991, Conan et al 1992).

Les différents traitements thermiques ou thermo-mécaniques appliqués aux pois sont susceptibles d'avoir des effets positifs et négatifs sur la digestibilité des protéines de pois.

\section{a / Inhibiteurs trypsiques}

Les inhibiteurs trypsiques du pois ont une structure très compacte, très résistante, en raison de leur teneur exceptionnellement élevée en ponts disulfure. Nous avons vu que cela leur conférait une résistance à l'hydrolyse enzymatique. Cette structure leur confêre également une certaine résistance à la dénaturation la chaleur. En conséquence, leur inactivation n'est atteinte qu'après des traitements assez drastiques: si la granulation à la vapeur $\left(80^{\circ} \mathrm{C}\right)$ n'est pas suffisante pour permettre leur inactivation, un autoclavage à $100^{\circ} \mathrm{C}$ pendant $15 \mathrm{~min}$, ou une cuisson-extrusion sont efficaces (Lessire et al 1988, Aumaitre et al 1992, Gatel 1992) pour permettre leur inactivation totale.

\section{b / Lectines}

Les traitements thermiques sont susceptibles d'inactiver les lectines, par dénaturation de leur structure. Cet effet est depuis très longtemps empiriquement connu : si les haricots communs (Phaseolus vulgaris) crus sont hautement toxiques, leur trempage suivi d'une cuisson adéquate permet leur consommation sans aucun danger! Comme pour les inhibiteurs trypsiques, la dénaturation (et donc l'inactivation) des lectines nécessite l'emploi de températures assez élevées ; la granulation à la vapeur ne semble pas affecter l'activité des lectines chez la féverole (Gatel 1992).

\section{c / Tanins}

Les traitements thermiques semblent diminuer légèrement la quantité de tanins dosés chez le haricot (Pastuszewska et al 1992). Les bases biochimiques de cette baisse restent néanmoins obscures. Le chauffage pourrait éventuellement diminuer leur capacité de liaison avec les protéines (Gatel 1992).

\section{d / Fibres}

Des traitements thermo-mécaniques tels que la granulation à la vapeur ou la cuissonextrusion sont susceptibles de détruire l'organisation cellulaire des pois (Carré et al 1991, Ben Hdech 1993). On peut donc supposer que les protéines seront plus accessibles à l'hydrolyse enzymatique après ce type de traitement.

\section{e / Phytates}

Peu de travaux ont été consacrés à l'effet des traitements technologiques sur les phytates. Chez la lentille, un traitement thermique appliqué après trempage semble diminuer la quantité de phytates dosés de $30 \%$ environ (Gorospe et al 1992).

\section{f / Structure résistante des protéines}

Nous avons vu dans les deux premiers chapitres que la plupart des protéines du pois possédaient une structure relativement compacte, rigide, leur conférant une résistance assez importante à l'hydrolyse enzymatique. Tout traitement affectant cette structure conduira donc à une augmentation de la susceptibilité à l'hydrolyse des protéines de pois. Un traitement par la chaleur $\left(99^{\circ} \mathrm{C}\right.$, protéines en solution, 10 à $30 \mathrm{~min}$ ) dénature les protéines de type $11 \mathrm{~S}$ ou $7 \mathrm{~S}$ et permet en général d'accroitre considérablement leur susceptibilité à l'hydrolyse enzymatique (Nielsen et al 1988).

Néanmoins, les traitements technologiques appliqués aux protéines en alimentation animale sont susceptibles de s'effectuer dans des conditions différentes de celles précédemment citées : les protéines sont en général en milieu peu hydraté, leur concentration est élevée, les températures appliquées peuvent dépasser $100^{\circ} \mathrm{C}$, et un grand nombre de constituants (autres protéines, sucres...) sont présents. Dans ces conditions, la dénaturation des protéines peut s'accompagner d'autres réactions. Une fois dénaturées, les 
différentes chaînes polypeptidiques sont susceptibles d'établir de nouvelles liaisons entre elles (réticulation), ce qui conduit à leur agrégation et à leur insolubilisation. Des phénomènes d'insolubilisation des protéines interviennent peu lors de chauffages à $100{ }^{\circ} \mathrm{C}$ (Nielsen et al 1988), mais sont capables de provoquer la presque totale insolubilisation des protéines lors de traitements plus drastiques tels que la cuisson-extrusion (BenHdech 1993). Les liaisons formées, impliquant généralement les résidus lysine et acide glutamique, sont résistantes à l'hydrolyse enzymatique. L'insolubilisation des protéines, très néfaste lorsqu'il s'agit d'aliments pour monogastriques, peut se révéler au contraire intéressante dans le domaine de l'alimentation des ruminants, où elle permet de limiter la dégradation ruminale des protéines (Benchaar et al 1992).

De plus, un chauffage des protéines en présence de sucres réducteurs (fructose, lactose...) conduit à la formation de nombreux polymères complexes, impliquant notamment la lysine. Cette réaction, appelée brunissement non enzymatique ou réaction de Maillard, contribue aussi à diminuer la digestibilité des protéines.

Enfin, le chauffage peut également induire des phénomènes de racémisation des acides aminés, c'est-à-dire leur passage de la forme $\mathrm{L}$, naturelle, à la forme $\mathrm{D}$, qui n'est plus reconnue par les enzymes digestives (Zagon et al 1994).

\section{g / Allergénicité des protéines}

La dénaturation des protéines, précédemment citée comme favorable à leur hydrolyse, pourrait également diminuer leur allergénicité en détruisant certains épitopes (Toullec et al 1992). Néanmoins, on peut également supposer que, consécutivement à la réaction de Maillard, de nouveaux épitopes allergéniques soient créés. Ainsi, on suppose que les produits de la réaction entre le lactose et la lysine de la $\beta$-lactoglobuline seraient un des allergènes du lait pasteurisé (Tomé 1991).

\section{3 / Technologies séparatives}

\section{a / Décorticage}

Le décorticage consiste à retirer mécaniquement le tégument séminal du pois (la coque). Chez le pois, le tégument n'est pas adhérent au reste de la graine, et cette opération s'en trouve facilitée.

Les coques de pois sont essentiellement composées de fibres (cellulose, xylanes, substances pectiques), celles des pois colorés contiennent en plus la totalité des tanins de la graine. Leur poids correspondant à environ $10 \%$ de celui de la graine, leur retrait enrichit donc les pois en protéines et en amidon, composés intéressants du point de vue nutritionnel.

Le décorticage, en diminuant la quantité de fibres présentes dans le pois (mais pas totale- ment, puisqu'il existe des fibres internes), permettrait donc de diminuer les effets supposés négatifs de ce facteur : limitation de l'accessibilité des protéines aux enzymes et/ou augmentation de la perte de protéines endogènes. Il permet aussi d'éliminer totalement les effets négatifs dus à la présence de tanins dans les pois colorés.

\section{b / Séparation des constituants principaux du pois}

La séparation des différents constituants (fibres, amidon, isolat protéique) est possible à partir du pois, par fractionnement en milieu aqueux (Gueguen 1983) ou par turboséparation (Sosulski 1983). Néanmoins, ces technologies assez coûteuses ne s'appliquent, jusqu'à présent, qu'à des produits destinés à l'alimentation humaine. Le Guen (1993) a introduit des isolats protéiques de pois (obtenus par fractionnement en milieu aqueux) dans des régimes pour porcelets comme unique source de protéines. La digestibilité iléale apparente mesurée est de $84 \%$, contre $69 \%$ pour les protéines de pois entier. Ce résultat peut s'expliquer par l'élimination des fibres, susceptibles d'exercer une influence négative sur la digestibilité des protéines, mais également par celle des inhibiteurs trypsiques, petites protéines éliminées lors de la préparation de l'isolat protéique. De plus, la préparation de l'isolat pourrait également provoquer des changements de structure de certaines protéines, favorisant leur susceptibilité à l'hydrolyse.

En conclusion, on peut donc remarquer que les effets des traitements technologiques concernent probablement plusieurs facteurs, et il apparaît difficile de les distinguer individuellement. Si, chez la volaille, les bénéfices de ces traitements ont été démontrés, chez le porc, seule la séparation des protéines des autres constituants du pois a permis d'obtenir des valeurs de digestibilité élevée. L'absence d'effets démontrés dans les autres cas peut-être due à l'existence, en parallèle, d'effets bénéfiques et néfastes des différents traitements technologiques: si un chauffage intense (supérieur à $100^{\circ} \mathrm{C}$ ) est recommandé pour l'inactivation des inhibiteurs trypsiques et lectines, celui-ci risque en même temps de conduire à une insolubilisation des principales protéines, et à une baisse de leur susceptibilité à l'hydrolyse.

\section{Conclusion}

L'utilisation du pois dans les régimes pour animaux monogastriques se traduit par une assez grande variabilité des performances zootechniques, et par une digestibilité des protéines légèrement inférieure à celle des régimes témoins (soja). Si les causes exactes de la limitation de la digestibilité des protéines du pois ne sont pas encore identifiées, de nombreuses hypothèses ont été émises, et de nombreux travaux de recherches s'intéres- 
sent à ce problème. Différents traitements technologiques peuvent être appliqués au pois et sont susceptibles d'en améliorer la valeur nutritionnelle. L'équilibre entre les influences positives et négatives de ces traitements paraît néanmoins difficile à établir. Les technologies visant à séparer les protéines des autres constituants de la graine ont conduit aux meilleurs résultats de digestibilité, mais sont les plus coûteuses.

De plus, la production du pois est en partie liée à l'existence d'aides communautaires à la production, aujourd'hui considérablement remises en cause par la réforme de la PAC. Quel est, dans ces conditions, l'avenir du pois en alimentation animale? Il reste une alternative possible au soja, mais ce dernier bénéficie d'un faible coût, et surtout d'une "assurance qualité " actuellement supérieure à celle du pois. On peut noter que ces avantages du soja par rapport au pois sont entiè- rement dus au fait que "l'aliment soja " est en fait un co-produit issu de la trituration des graines de soja pour en extraire l'huile : il a donc subi des traitements technologiques (broyage, chauffage), améliorant considérablement sa teneur en protéines et sa valeur nutritionnelle. L'avenir du pois serait-il dans la valorisation (alimentaire ou non) de sa fraction non protéique? Les fibres de pois présentent en effet des caractéristiques intéressantes pour l'alimentation humaine (incolores, inodores) et l'amidon de pois a été utilisé, avec succès, pour la fabrication de biomatériaux.

\section{Remerciements}

L'auteur remercie vivement J.P. Melcion, du Laboratoire de Technologie Appliquée à la Nutrition et G. Viroben, du Laboratoire de Biochimie et Technologie des Protéines, pour la relecture efficace de ce texte.

\section{Références bibliographiques}

Aumaitre A., Peiniau J., Bengala Freire J., Seve B. 1992. Sensitivity of the weaned piglet to pea antinutritional factors : effect of technological treatments. Première conférence européenne sur les protéagineux, Angers, France, 487-488.

Baniel A., 1993. Etude de la variabilité génotypique et phénotypique de la composition protéique du pois (Pisum sativum $L$.). Thèse de doctorat, Université de Nantes.

Barrier-Guillot B., Castaing J., Peyronnet C., Lucbert J., 1992. Comparison of pea varieties (Pisum sativum $\mathrm{L}$.) varying in their trypsin inhibitor activity on broiler performance. Première conférence européenne sur les protéagineux, Angers, France, 527-528.

Begbie R., Ross A.W., 1993. Resistance of the kidney bean reserve protein, phaseolin, to proteolysis in the porcine digestive tract. J. Sci. Food Agric., 61, 301307.

Benchaar C., Bayourthe C., Moncoulon R., Vernay $\mathrm{M}, 1992$. Effect of extruding horsebeans at $195^{\circ} \mathrm{C}$ on protein behaviour in the digestive tract of lactating cows. Première conférence européenne sur les protéagineux, Angers, France, 491-492.

Bengala-Freire J., Aumaitre A., Peiniau J., 1991 Effects of feeding raw and extruded peas on ileal digestibility, pancreatic enzymes and plasma glucose and insulin in early weaned pigs. J. Anim. Physiol. Anim. Nutr., 65, 154-164.

Ben-Hdech H., 1993. Texturation d'une farine de pois par cuisson-extrusion : caractérisation microstructurale, ultrastructurale et physico-chimique. Thèse de doctorat, Université de Nantes.

Bertrand G., Seve B., Gallant D.J., Tome D., 1988. Absence d'effets antinutritionnels des lectines de pois, sous forme native ou purifiée, chez le porcelet. Comparaison avec les lectines natives de soja. Sci. Aliments, 8, 187-212.
Birk Y., Smirnoff P., 1992. Protein protease inhibitor from legume seeds and their significance in nutrition, pest control and medicine. Première conférence européenne sur les protéagineux, Angers, France, 391-392.

Boulter D., Evans I.M., Ellis J.R., Shirsat A., Gatehouse J.A., Croy R.R.D., 1987. Differential gene expression in the development of Pisum sativum Plant Physiol. Biochem., 25, 283-289.

Bradbear N., Boulter D., 1984. The use of enzymic hydrolysis in vitro to study the digestibility of some phaseolus seed proteins. Qual. Plantarum : Plant Foods Hum Nutr., 34, 3-13.

Carré B., Beaufils E., Melcion J.P., 1991. Evaluation of protein and starch digestibilities and energy value of pelleted or unpelleted pea seeds from winter or spring cultivars in adults and young chickens. J. Agric. Food Chem., 39, 468-472.

Conan L., Barrier-Guillot B., Widiez J.L., Lucbert J. 1992. Effect of grinding and pelleting on the nutritional value of smooth pea seeds (Pisum sativum) in adult cockerel. Première conférence européenne sur les protéagineux, Angers, France, 479-480.

Croy R. R. D., Hoque M.S., Gatehouse J.A., Boulter D., 1984. The major albumin proteins from pea (Pisum sativum L.). Purification and some properties. Biochem. J., 218, 795-803.

Darcy B., 1984. Availability of amino acids in monogastric animals. Variations of digestive origin. Diabète et métabolisme, 10, 121-133.

Dreau D., 1994. Hypersensibilité aux protéines de soja chez le porcelet et le veau préruminant. Thèse de doctorat, Ecole nationale supérieure agronomique de Rennes.

Gatehouse J.A., Gilroy J., Hoque M.S., Croy R.R.D. 1985. Purification, properties and amino acid sequence of a low- $\mathrm{M}_{\mathrm{r}}$ abundant seed protein from pea (Pisum sativum L.). Biochem. J., 225, 239-247. 
Gatel F., 1992. Protein quality for monogastric animals. Première conférence européenne sur les protéagineux, Angers, France, 461-474.

Goldstein I.J., Poretz R.D., 1986. Isolation, physicochemical characterization, and carbohydrate-bin ding specificity of lectins. In Liener, I.E., Sharon, N., Goldstein, I.J (Eds) «The lectins. Properties, functions, and applications in biolology and medicine", Harcourt Brace Jovanovitch (Publishers), Academic press, Orlando, 33-248.

Gorospe M. J., Vidal-Valderve C., Frias J., 1992. The effect of processing on phytic acid content of lentils. Recueil de communications, Première conférence européenne sur les protéagineux. Angers, France, 425-426.

Grant G., Van Driessche E., 1993. Legume lectins physicochemical and nutritional properties. In : Van der Pœl A.F.B., Huisman J., Sani H. S. (Eds) "Recent advances of research in antinutritional factors in legume seeds". Proceeedings of the second international workshop on antinutritional factors in legume seeds, Wageningen, The Netherlands, 1-3 December 1993, 219-233.

Grosjean F., Bourdon D., Kiener T., Castaing J., Gatel F., 1991. Valeur alimentaire pour les porcs des pois français et étrangers. Journées Rech. Porcine en France, 23, 53-60.

Gruen L. C., Guthrie R. E., Blagrove R. J., 1987. Structure of a major pea seed albumin. Implication of a free sulphydryl group. J. Sci. Food Agric., 41, 167-178.

Gruppen H., De Groot J., Van Oort M.G., 1993. Identification and partial isolation of an antigenic protein in Pisum sativum cv. Solara. In : Van Der Pol A.F. B., Huisman J., Sani H. S. (Eds) "Recent advances of research in antinutritional factors in legume seeds ". Proceedings of the second international workshop on antinutritional factors in legume seeds, Wageningen, The Netherlands, 1-3 December 1993, 293-297.

Gueguen J., 1983. Legume seed protein extraction, processing and end product characteristics. Qual. Plantarum : Plant Food Hum. Nutr., 32, 268-303.

Gueguen J., 1991. Pea and fababean proteins. In Hudson, B.J.F., (Ed.) « Development in food proteins - 7. ", Elsevier Applied Science, London, 35-78.

Gueguen J., Barbot J., 1988. Quantitative and qualitative variability of pea (Pisum sativum L.) protein composition. J. Sci. Food Agric., 42, 209-224.

Gwiazda S., Schwenke K.D. Rutowski A., 1980. Isolation and partial characterization of proteins from pea (Pisum sativum L.). Nahrung, 24, 939-950.

Hall D.D., Fernandez J.A., Jorgensen H.J., Boisen S., 1988. Prediction of ileal and fecal digestibility of crude protein and amino-acids in pigs by NDF and NDF-nitrogen analyses. Wiss. Z. WPU Rostock N. Reihe, 37, 54-55.

Hamer R.J., Vlooswijk R., Van Oort M.G., 1992. Antigenicity of legume proteins in animal feeding. Première conférence européenne sur les protéagineux, Angers, France, 453-454.

Higgins, T.J.V., 1984. Synthesis and regulation of major proteins in seeds. Ann. Rev. Plant Physiol., $35,191-221$.

Higgins T.J.V., Chandler P.M., Randall P.J., Spencer D., Beach L.R., Blagrove R.J., Kortt A.A., Inglis A.S., 1986. Gene structure, protein structure, and regulation of the synthesis of a sulfur-rich protein in pea seeds. J. Biol. Chem., 261, 11124-11130

Huisman J., 1991. Antinutritional effects of legume seeds in piglets, rats and chickens. Thèse de doctorat, Université d'agriculture de Wageningen.

Huisman J., Jansman A. J. M., 1991. Dietary effects and some analytical aspects of antinutritional factors in pea (Pisum sativum), common beans (Phaseolus vulgaris) and soyabeans (Glycine $\max L$.) in monogastric farm animals. A literature review. Nutrition abstracts and reviews (series B), 61, 901921.

Kakade M.L., Hoffa D.E., Liener I.E., 1973. Contribution of trypsin inhibitors to the deleterious effects of unheated soybeans fed to rats. J. Nutr., 103, 1772-1778

Knuckles B.E., Kuzmicky D.D., Gumbmann M.R., Betschart A.A., 1989. Effect of myo-inositol phosphate esters on in vitro and in vivo digestion of protein. J. Food Sci., 54, 1348-1350.

Kunitz M., 1945. Crystallisation of a trypsin inhibitor from soybeans. Science, 101, 668-669.

Lacassagne L., Melcion J.P., De Monredon F., Carre B., 1991. The nutritional values of fababean flours varying in their mean particle size in young chic kens. Anim. Feed Sci. Technol., 34, 11-19.

Lallès J. P., 1993. Nutritional and antinutritional aspects of soyabean and field pea proteins used in veal calf production : a review. Livest. Prod. Sci., 34, 181-202.

L'anson, K. J., Miles, M. J., Bacon, J. R., Carr, H. J., Lambert, N., Morris, V. J., Wright, D. J., 1988. Structure of the $7 \mathrm{~S}$ globulin (vicilin) from pea (Pisum sativum). Int. J. Biol. Macromol., 10, 311317.

Le Guen M.P., 1993. Pea proteins for piglets : effects on digestive processes. Thèse de doctorat, Université d'agriculture de Wageningen.

Lessire M., Leclercq B., Conan L., 1988. Variabilité de la valeur énergétique de la graine de soja traitée pour les volailles. INRA Prod. Anim., 1 (4), 265-270.

Leterme P., Beckers Y., Thewis A., 1990. Trypsin inhibitors in peas : varietal effects and influence on digestibility of crude protein by growing pigs. Anim. Feed Sci. Technol., 29, 45-55.

Leterme P., Monmart T., Thewis A., 1992. Varietal distribution of trypsin inhibitors in peas. Première conférence européenne sur les protéagineux, Angers, France, 417-418.

Marinos, N.G., 1970. Embryogenesis of the Pea (Pisum sativum). I. The cytological environment of the developing embryo. Protoplasma, 70, 261-279.

Masson P., Tome D., Gaborit T., 1986. Large-scale preparation and characterization of pea seed lectins (Pisum sativum L.). Lebensm. Wiss. Technol., 19, 138-143.

Mathis C., 1991. Etude quantitative (ELISA) de la digestion intestinale de la glycinine et de la $\beta$-conglycinine du soja chez le veau préruminant. Diplôme d'Etudes Approfondies, Université Rennes I.

Matta N.K., Gatehouse J.A., Boulter D., 1981. Molecular and subunit heterogeneity of legumin of Pisum sativum L. (garden pea) - a multi-dimensional gel electrophoretic study. J. Exp. Bot., 32, 12951307.

Mendel G., 1865. Versuche über Plfanzenhybriden. Verh. naturf. Ver. Brünn, 4, 3-47. 
Nakata S., Kimura T., 1985. Effects of ingested toxic bean lectins on the gastrointestinal tract in the rat. J. Nutr., 115, 1621-1629.

Nielsen S.N., Deshpande S.S., Hermodsen M.A., Scott M.P., 1988. Comparative digestibility of legume storage proteins. J. Agric. Food Chem., 36, 896-902.

Nunes Do Prado I., Toullec R., Lallès J.P., Gueguen J., Hingand J., Guilloteau P., 1989. Digestion des protéines de pois et de soja chez le veau préruminant. I. Taux circulants de nutriments, formation d'anticorps et perméabilité intestinale aux macromolecules. Reprod. Nutr. Develop., 29, 413-424.

Osborne T.B., Campbell G.R., 1898. Proteins of the pea. J. Amer. Chem. Soc., 20, 348-410.

Pastuszewska B., Smulikowska S., Chibowska M., Janowska G., 1992. Effect of dehulling and heat treatment on protein and energy value of field bean. Première conférence européenne sur les protéagineux, Angers, France, 475-476.

Perez J.M., Bourdon D., 1992. Energy and protein value of peas for pigs: synthesis of french results. Recueil de communications. Première conférence européenne sur les protéagineux, Angers, France, $489-490$

Perrot C., 1994. Susceptibilité à l'hydrolyse enzymatique des protéines de pois (Pisum sativum L.). Thèse de doctorat, options sciences alimentaires. Université Paris 7.

Plietz P., Zirwer D., Schlesier B., Gast K., Damaschun G., 1984. Shape, symetry, hydration and secondary structure of the legumin from Vicia faba in solution. Biochem. Biophys. Acta, 784, 140-146.

Plumb G. W., Lambert N., 1990. A comparison of the trypsinolysis products of nine $11 \mathrm{~S}$ globulin species. Food hydrocolloids, 3, 465-473.

Pusztai A., Begbie R., Grant G., Ewen S.W.B., Bardocz S., 1991. Indirect effects of food antinutrients on protein digestibility and nutritional value of diets. In Fuller M.F. (Ed.) "In vitro digestion for pigs and poultry ", C.A.B. International, Wallingford, $\operatorname{ch~4,~45-61~}$

Quemere P., 1990. Synthèse des essais français et étrangers sur l'utilisation du pois protéagineux par les porcins (porcelets, porcs charcutiers et truies). Journées Rech. Porcine en France, 22, 148-165.
Royer A., 1975. Inhibiteurs d'enzymes protéolytiques et protéases des graines. In Miege J. « Les protéines des graines ", Georg editeur, Genève, 159202.

Schroeder H. E., 1984. Major albumins of Pisum cotyledons. J. Sci. Food Agric., 35, 191-198.

Shutov A. D., Vaintraub I. A., 1987. Degradation of storage proteins in germinating seeds. Phytochem., $26,1557-1566$.

Sosulski F. W., 1983. Legume protein concentration by air-classification. In : Developments in food proteins, vol 2, (B.J.F. Hudson, Ed), Applied Sci. Publ., London, 173-213.

Stanogias G., Pearce, G.R., 1985. The digestion of fibre by pigs. 1/ The effects of amount and type of fibre on apparent digestibility, nitrogen balance and rate of passage. Br. J. Nutr., 53, 513-530.

Subirade M., Gueguen J., Pezolet M., 1994. Conformational changes upon dissociation of a globular protein from pea : a Fourier-transformed infrared spectroscopic study. Bioch. Biophys. Acta, 1205, 239 247.

Tomé D., 1991. Digestibilité des protéines en fonction de la taille des fractions protéiques. Med. et Nutr., T XXVII, 129-132.

Tomé D., Dhoye C., Gaborit T., Kozlowski A., Valdebouze P., 1981. Extraction et séparation des inhibiteurs trypsiques de la graine de pois (Pisum sativum L.). Sci. Aliments, 1, 587-601

Toullec R., Lallès J.P., Guilloteau P., 1992. Effect of flacking on pea flour utilization in milk replacers for veal calves. Première conférence européenne sur les protéagineux. Angers, France, 497-498.

UNIP-ITCF, 1993. Pois : utilisation en alimentation animale. Edition ITCF, Boigneville.

Weder J.P.K., 1986. Inhibition of human proteinases by grain legumes. Adv. Exp. Med. Biol., 199, 239279 .

Wenzel M., Gers-Barlag H., Schimpl A., Rudiger H., 1993. Time course of lectin and storage protein biosynthesis in developping pea (Pisum sativum) seeds. Biol. Chem. Hoppe-Seyler, 374, 887-894.

Zagon J., Dehne L-I, Bogl K-W, 1994. D-amino acids in organism and food. Nutr. Research, 14, 445-463.

\begin{abstract}
Pea proteins : from their function in the seed to their use in animal nutrition.

Pea is a protein-rich crop of European origin of particular interest for use in animal nutrition (monogastrics). The main function of proteins in the seed is to constitute a reserve of nitrogen and amino-acids. As a result, these proteins have developed certain characteristics: they are very compact in nature-and resistant to hydrolysis before germination. In animal nutrition, pea protein digestibility is variable, and generally lower than soya protein (control diets). Protein digestibility can be limited at different steps of digestion : at the step of hydrolysis by digestive enzymes, during the absorption of hydrolysis
\end{abstract}

Abstract products, or by a reaction of animals to the diets, that could result in an increase in endogenous proteins loss. Different hypotheses have been proposed to explain the limitation of pea protein digestibility : trypsin inhibitors, lectins, fibres, the particular structure of proteins and their antigenic nature. The application of various technological treatments may have positive (protein denaturation, inhibitors inactivation, loss of cellular structures) or negative effects (reticulation, insolubilisation) on pea protein digestibility

PERROT C., 1995. Les protéines de pois : de leur fonction dans la graine à leur utilisation en alimentation animale. INRA Prod. Anim., 8 (3), 151-164. 